\title{
Regional Differentials in Early Antenatal Care, Health Facility Delivery and Early Postnatal Care
} among Women in Uganda

\author{
Ruth Atuhaire ${ }^{1}$, Robert Wamala², Leonard K Atuhaire ${ }^{3}$, Elizabeth Nansubuga ${ }^{4}$ \\ ${ }_{1}^{1}$ Department of Management Science, Makerere University Business School, Kampala, Uganda \\ 2,3,4 Department of Planning and Applied Statistics, Makerere University School of Statistics and Planning, \\ Kampala, Uganda \\ ratuhaire@mubs.ac.ug,wamalar@gmail.com, leonardatuhaire@gmail.com, enansubuga@gmail.com
}

\begin{abstract}
This study aimed at examining regional differentials in maternal healthcare services in Uganda. Using a sample of 1,521 women of reproductive ages (15-49) from Eastern and Western sub-regions of Uganda, and non-linear Oaxaca' Blinder Multivariate Decomposition method, we assessed differentials in utilization of early antenatal care, health facility delivery and early postnatal care services among the women, henceforth, establishing main predictors of regional inequalities that will enable policymakers to make better evenly interventions and focused decisions. The study reveals that differentials in the utilization of maternal healthcare services are not only hindered by social and economic barriers, but also widespread disparities in the utilization of existing services. Significant differentials were attributed to both variation in women's characteristics and effects of coefficients. Findings showed that the gap in early antenatal care would reduce on average by $31.6 \%$ and $34.7 \%$ of differences in availability of community health workers and media exposure respectively, were to disappear. Furthermore, the gap would increase on average by $68.8 \%$ and $12.6 \%$ in absence of the variation in effects of maternal education, and wealth respectively. The gap in health facility delivery would reduce on average by $24.6 \%$ and $37.2 \%$ of differences in community health worker availability and media exposure were to disappear respectively and increase on average by $54.9 \%$ in the absence of variations in effects of maternal education. The gap in EPNC would reduce on average by $18.5 \%$ and $17.17 \%$ of differences in maternal education and community health worker availability were to disappear respectively and increase on average by $52.8 \%$ and $8.4 \%$ in the absence of the variation in effects of maternal education and wealth respectively. Progress towards equitable maternal health care should focus more on strategies that guarantee even distribution of community health workers, broad dissemination of maternal healthcare information and girl child education completion in Uganda.
\end{abstract}

Keywords: Regional decomposition, Oaxaca' Blinder, Early ANC, health facility delivery, EPNC.

\section{Introduction}

Maternal health is one of the ultimate rights of every woman to be enjoyed, without distinction of demographic, social or economic conditions (WHO, 2017). According to United Nations Children's Fund (UNICEF), a newborn or expectant mother dies somewhere in less than half a minute from circumstances that may perhaps be avoided and averted (UNICEF, 2019). Every day, approximately 810 women die globally from pregnancy-related complications, and inequalities to quality maternal health services still exist (WHO, 2019). Equal and early care make it possible for health workers to evenly offer maternal care among women, and discover avoidable and or preventable complications on time (Bbaale \& Guloba, 2011; Rice, 2019; Rutaremwa, Wandera, Jhamba, Akiror, \& Kiconco, 2015; UNICEF, 2019). Different studies in developing countries have attributed uneven and delayed utilization in Maternal Health Care Service (MHCS) utilization to a combination of reasons such as distance to a hospital or clinic, cost of receiving services, different income levels, maternal age, maternal education, availability of community workers.

Parity and exposure to maternal health information (Emelumadu et al., 2014; Golooba-Mutebi, 2011 Ricketts \& Goldsmith, 2005 Wudineh, Nigusie, Gesese, Tesu, \& Beyene, 2018). Safe Motherhood programs (SMP) and the Uganda National Population Policy sought to address reasons for uneven and delayed maternal health care accessibility by promoting informed choice, equitable and improved quality of Maternal and Infant health care. Equity in the health sector has long been considered an essential objective of the health system (Houweling, Ronsmans, Campbell, \& Kunst, 2007; WHO, 2015b). However, low use of maternal health services coupled with enormous spatial disparities requires a significant shift to increase better service coverage and better policy formulation (Adeyanju, Tubeuf, \& Ensor, 2017; Fang et al., 2010; Pallikadavath, Foss, \& Stones, 2004b). Even distribution of MHCS and early care is essential in preventing and lowering 
mortality and or mortality keeping the mother and her newborn healthy (Kerber et al., 2007; UBOS, 2017). Even though Uganda over the years registered progress in maternal health wellness programs, regional disparities were evident in the early utilization of maternal care services (UBOS, 2017).

Besides, the country's maternal mortality rate is still among the highest globally at 440 deaths per 100,000 live births (Rice, 2019; UNICEF, 2019) compared to the average target of 70 deaths per 100,000 live births (Norton, 2016). Uganda's strive after the United Nations (UN) proposed Sustainable Development Goal 3.1 on lowering maternal mortality and Goal 10 regarding reduced inequalities can be accomplished by better interventions aiming at even distribution and early MHCS access (WHO, 2015a, 2015b). Therefore, the importance of this study is to establish regional differentials in the utilization of early antenatal care, health facility delivery and early postnatal care in Uganda. This research contributes towards an improved understanding of balanced interventions regarding equity, early maternal healthcare utilization, and quality of care that will assist policymakers to focus their interventions and create better decisions.

\section{Literature Review}

Fairness in the health sector is considered a vital goal of every health system (Houweling et al., 2007; WHO, 2015b). According to Pallikadavath et al. (2004b), low use of maternal health services coupled with enormous regional disparities with socio-economic and cultural changes require a substantial change in priorities to increase better service coverage and better policy formulation. A study by Magadi, Zulu, and Brockerhoff (2003) revealed that maternal health inequalities are still high in most areas across nations of sub-Saharan Africa. In most developing countries, inequalities were evident due to differentials in distance to the health facility, age, clinic availability, maternal education (Say \& Raine, 2007) and availability of government health workers (Pal, 2015). In Malawi, inequalities were mainly because of different geographical locations, education and wealth (Yaya, Bishwajit, \& Shah, 2016). In Nigeria, access to health facility delivery had greater levels of inequalities and was determined mainly by the less educated, poor and rural dwellers (Adeyanju et al., 2017). This was further confirmed in China (Liu, Gao, \& Yan, 2014) and Bangladesh, (Khan, Islam, \& Rahman, 2018). In India, pregnant women from impoverished backgrounds with many children were the least likely to obtain prenatal check-ups and services in the major northern zones (Pallikadavath, Foss, \& Stones, 2004a).

A study carried out in Namibia showed that women with a high level of education residing in urban places, originating from regions with high human development indicators had a higher utilization factor of maternal health care services (Zere, Oluwole, Kirigia, Mwikisa, \& Mbeeli, 2011). In the presence of inequities, it is hard to reduce maternal mortality ratios and identify better maternal interventions for different groups (Liu et al., 2014). Among North African countries, maternal utilization services are unevenly enjoyed by distinct socioeconomic strata especially unacceptable differentials between the rich and poor (Boutayeb \& Helmert, 2011), large urban-rural disparities in Vietnam (Tran et al., 2011), differences between privileged and underprivileged cities in USA (Alexander, Kogan, \& Nabukera, 2002). In Brazil, reduction in income inequalities among the wealthy and poor populations, improved maternal education, cash waivers, improvements in hygiene led to improved equality in maternal health utilization between different regions (Victora et al., 2011). In Uganda, despite the fact that women who live in Western regions had higher odds of utilizing maternal health care services (Rutaremwa et al., 2015), according to UBOS (2017), they had a low utilization factor in all maternal health services as compared to women from Eastern sub-region. Furthermore, household welfare, high maternal education levels and community knowledge about health, gradually reduce inequalities in health (Ssewanyana \& Kasirye, 2012).

Arthur (2012), reveals that considerable variations existed in the usage of prenatal care in different regions of Ghana due to insufficient health workers and facilities in some of the regions. Likewise, Rai, Singh, and Singh (2012) found that though most women deliver from institutions, the exposed with a good education utilized the services earlier compared to their counterparts. In China, regional health inequality was associated with different wealth quintiles and the availability of resources (Fang et al., 2010). In Nigeria, migrants, women with low education levels and incomes predicted inequalities and at the same time represented the common perception to judge MHCS gaps (Ononokpono \& Odimegwu, 2014). Furthermore, differentials in maternal outcomes were common in women from lower socioeconomic classes, certain ethnic groups, and living in 
suburbs (de Graaf, Steegers, \& Bonsel, 2013). Findings by Singh, Rai, Alagarajan, and Singh (2012) indicated that main variations in the use of maternal healthcare were associated with educational attainment, financial status and area of residence. The use of maternal health care and treatment services is not only associated with socio-economic and cultural issues but also with geographical places (Navaneetham \& Dharmalingam, 2002). Additionally, Lavado and Lagrada (2008) revealed that, in the Visayas, inequality in maternal and child health services utilization was more across regions. Houweling et al. (2007), findings on poor-rich differentials in maternity utilization in 45 developing countries revealed that, place of delivery nursing care favors the wealthy in most states.

\section{Methodology}

The Uganda Demographic and Health Survey (UDHS) conducted during the period 2015/16 were used in this study. This UDHS implemented by the Uganda Bureau of Statistics (UBOS) provides information on key demographic and population characteristics for giving up-to-date maternal health indicators. Consent and authorization to make use of the data were acquired from ICF Macro International U.S.A, DHS Program. Based on our previous study (Atuhaire, Atuhaire, Wamala, \& Nansubuga, 2020), 939 women from Eastern and 582 women from Western sub-regions were sampled. The selection was based on the two sub-regions having almost similar economic indicators but with different maternal healthcare utilization factors (UBOS, 2017). Using available information, we created three outcome variables defined as; early antenatal care (EANC) (women who utilized first antenatal care within the three months of pregnancy), health facility delivery (HFD) (women who had institutional deliveries) and early postnatal care (women who received the first PNC within 2 days after giving birth). The predictor variables included maternal age, education, wealth, marital status if the pregnancy was wanted or not, media exposure, complications during pregnancy, available health workers in the community if the distance to a health facility was problematic or not, and costs of service (Atuhaire et al., 2020).

Data Analysis: Data were processed and analyzed using STATA 13.0 (Stata, 2013). Descriptive summary statistics showing differentials in women's characteristics and a bar graph of the differences in the outcome variables were carried out. Thereafter, percentage differences in EANC, HFD and EPNC were distributed according to the demographic, social and economic characteristics obtained. Lastly, the Blinder-Oaxaca decomposition technique using a logistic model to partition differences between Eastern (A) and Western (B) sub-regions into components attributable to variation in women's characteristics and variation in the effect of coefficients fitted. The decomposition was based on equations (1), (2) and (3) as shown below:

$$
\bar{Y}_{A}-\bar{Y}_{B}=\overline{F\left(X_{A} \beta_{A}\right)}-\overline{F\left(X_{B} \beta_{B}\right)}
$$

The mean difference between women in different regions was further decomposed as below:

$$
\bar{Y}_{A}-\bar{Y}_{B}=\left\{\overline{F\left(X_{A} \beta_{A}\right)}-\overline{F\left(X_{B} \beta_{A}\right)}\right\}+\left\{\overline{F\left(X_{B} \beta_{A}\right)}-\overline{F\left(X_{B} \beta_{B}\right)}\right\}
$$

The above equation can be summarized as;

$$
\bar{Y}_{A}-\bar{Y}_{B}=E-C
$$

Where $\bar{Y}_{A}-\bar{Y}_{B}$ implies inequalities/differences in mean level outcomes between Eastern and Western subregions. The component $E$ denotes the part of the differential accountable to differences in characteristics. The component $C$ denotes the part of the differential attributable to variations in coefficients and $X \beta$ denotes the coefficients of characteristics of women. $F$ Follows a logistic function mapping $X(X \beta)$ to $Y$. Associations between the variables and differences attributed to compositional variations and predictor variations were established at $5 \%$ level of significance.

\section{Results and Discussion}

This section presents the descriptive characteristics of Eastern and Western women, the differences in EANC, HFD and EPNC between the women, decomposition of change in EANC, HFD and EPNC and discussion of results. Table 1 reveals that the main disparities in percent distribution of women by their characteristics were identified in maternal highest education level, distance to the health facility, wealth, availability of community health worker and media exposure. The findings reveal that more than $16 \%$ of women in the Western region have incomplete primary education compared to women from the Eastern region, and more than $14 \%$ of women in the Eastern region have some secondary education, this implies that more women in 
the Eastern sub-region have complete primary education as compared to women from Western sub-region. Furthermore, regarding the highest maternal level, in both regions, the majority of women had below primary level $47.1 \%$ for Eastern and $63.8 \%$ for Western in comparison to other categories.

In relation to wealth, a difference in distribution was observed among poor and rich women; the majority of women in the Western are poorer than those of the Eastern (14.7\%) sub-region and the proportion of rich women in Eastern is higher than those in Western sub-region (11.4\%). This finding agrees with Houweling et al. (2007) who revealed that EANC, HFD and EPNC utilization is much higher among rich households compared to poor households in developing countries. Additionally, results show that distance to reach the health facility is a bigger problem in the Western compared to the Eastern sub-region (8.5\%) and community health workers are more readily available in the Eastern (76.5\%) than in the Western sub region (56.9\%). There was a relatively large difference in the percentage distribution of women who were exposed to any form of media between Eastern and Western sub-regions (14.9\%). In addition, six out of every ten women in Eastern are exposed to media as compared to four out of ten women in the Western sub-region.

Table 1: Distribution by Characteristics of Women

\begin{tabular}{|c|c|c|c|}
\hline Characteristics & Eastern $(n=939)$ & Western (n=582) & Difference (\%) \\
\hline \multicolumn{4}{|l|}{ Age } \\
\hline $15-19$ & 28.13 & 31.75 & -3.62 \\
\hline $20-34$ & 61.78 & 58.24 & 3.54 \\
\hline $35-49$ & 10.09 & 10.01 & 0.89 \\
\hline \multicolumn{4}{|l|}{ Maternal Education Level } \\
\hline Below primary & 47.1 & 63.8 & -16.7 \\
\hline Completed primary seven & 14.6 & 13.3 & 1.3 \\
\hline Some secondary & 32.0 & 18.0 & 14 \\
\hline Completed secondary six & 6.3 & 4.9 & 1.4 \\
\hline \multicolumn{4}{|l|}{ Marital Status } \\
\hline Unmarried & 70.6 & 69.8 & 0.8 \\
\hline Married & 29.4 & 30.2 & -0.8 \\
\hline \multicolumn{4}{|l|}{ Wealth } \\
\hline Poor & 33.2 & 47.5 & -14.3 \\
\hline Middle & 25.9 & 23.0 & 2.90 \\
\hline Rich & 40.9 & 29.5 & 11.4 \\
\hline \multicolumn{4}{|l|}{ Distance to Health Facility } \\
\hline Not big problem & 60.3 & 51.8 & 8.5 \\
\hline Big problem & 39.7 & 48.2 & -8.5 \\
\hline \multicolumn{4}{|l|}{ Cost of Service } \\
\hline Not big problem & 56.0 & 52.8 & 3.2 \\
\hline Big problem & 44.0 & 47.2 & -3.2 \\
\hline \multicolumn{4}{|c|}{$\begin{array}{l}\text { Availability of a Health Worker } \\
\text { in Community }\end{array}$} \\
\hline Not readily available & 23.5 & 43.1 & -19.6 \\
\hline Readily available & 76.5 & 56.9 & 19.6 \\
\hline \multicolumn{4}{|l|}{ Exposure to media } \\
\hline Not exposed to media & 37.7 & 52.6 & -14.9 \\
\hline Exposed to media & 62.3 & 47.4 & 14.9 \\
\hline \multicolumn{4}{|l|}{ Pregnancy Wanted } \\
\hline No & 26.2 & 27.1 & -0.9 \\
\hline Yes & 73.8 & 72.9 & 0.9 \\
\hline \multicolumn{4}{|l|}{ Complications } \\
\hline No & 97.4 & 96.5 & 0.9 \\
\hline Yes & 2.60 & 3.50 & -0.9 \\
\hline
\end{tabular}


Table 2 presents the weighted differences between Eastern and Western women by their characteristics, who are summarized as follows: EANC was higher for women who completed senior six (advance level) (Eastern $36.8 \%$ and western $32 \%)$ with a percentage difference of $4.8 \%$, the unmarried $(21.8 \%$ and $17.8 \%(=4 \%))$ and among the rich $(26 \%$ and $22.2 \%(=3.8 \%))$. However, the main difference was observed among women with some primary education levels $(21.5 \%$ and $15.9 \%(=5.6 \%))$. The percentage difference in HFD between Eastern and Western was high in a community with readily available health workers $(80.4 \%$ and $58.7 \%$ $(=21.7 \%))$. However, there was a slight difference in HFD between Eastern and Western women who completed senior six $(78.2 \%$ and $75.8 \%(=2.4 \%))$, and those with the cost of service problems $(72.8 \%$ and $70.3 \%(=2.5 \%))$. Percentage differences in EPNC between Eastern and Western women were higher among those who completed senior six $(53.8 \%$ and $38 \%(=15.8 \%))$ and among women without distance to the health facility problems $(41.3 \%$ and $3.3 \%(=11.0 \%))$. EPNC was higher among the rich quintile for Eastern and Western women $(60.2 \%$ and $54.7 \%)$ respectively.

Table 2: Differences in EANC, HFD and EPNC between Women in Eastern and Western sub Regions Distributed by Background Characteristics

\begin{tabular}{|c|c|c|c|c|c|c|}
\hline \multirow[t]{2}{*}{ Characteristics } & \multirow{2}{*}{$\begin{array}{l}\text { Early ANC } \\
\text { Eastern }\end{array}$} & \multirow[b]{2}{*}{ Western } & \multicolumn{2}{|c|}{ Health Facility delivery } & \multirow{2}{*}{$\begin{array}{l}\text { EPNC } \\
\text { Eastern }\end{array}$} & \multirow[b]{2}{*}{ Western } \\
\hline & & & Eastern & Western & & \\
\hline \multicolumn{7}{|l|}{ Age } \\
\hline $15-19$ & 29.9 & 27.2 & 54.0 & & 39.9 & 34.2 \\
\hline $20-34$ & 23.2 & 21.5 & 58.8 & & 43.1 & 36.5 \\
\hline $35-49$ & 27.8 & 26.8 & 63.0 & & 41.8 & 37.8 \\
\hline \multicolumn{7}{|l|}{ Maternal Education } \\
\hline Below primary & 21.5 & 15.9 & 74.8 & 58.1 & 36.5 & 30.1 \\
\hline Completed primary 7 & 21.9 & 21.9 & 76.7 & 60.9 & 39.7 & 36.9 \\
\hline Some secondary & 33.8 & 31.8 & 78.0 & 69.8 & 40.2 & 36.8 \\
\hline $\begin{array}{l}\text { Completed secondary } \\
\text { six }\end{array}$ & 36.8 & 32.0 & 78.2 & 75.8 & 53.8 & 38.0 \\
\hline \multicolumn{7}{|l|}{ Marital Status } \\
\hline Unmarried & 21.8 & 17.3 & 76.8 & 56.3 & 39.8 & 36.3 \\
\hline Married & 24.0 & 21.4 & 78.0 & 58.4 & 43.0 & 38.9 \\
\hline \multicolumn{7}{|l|}{ Wealth } \\
\hline Poor & 20.2 & 20.8 & 77.2 & 57.8 & 38.2 & 37.9 \\
\hline Middle & 27.7 & 25.4 & 80.7 & 58.4 & 43.7 & 38.4 \\
\hline Rich & 22.2 & 26.0 & 79.2 & 60.2 & 60.2 & 54.7 \\
\hline \multicolumn{7}{|l|}{ Distance to Facility } \\
\hline Not big problem & 29.7 & 27.4 & 79.7 & 60.4 & 40.7 & 37.4 \\
\hline Big problem & 21.3 & 23.5 & 75.3 & 57.0 & 41.3 & 30.3 \\
\hline \multicolumn{7}{|l|}{ Costs of Service } \\
\hline Not big problem & 23.8 & 22.3 & 72.8 & 70.3 & 43.8 & 39.1 \\
\hline Big problem & 21.2 & 21.5 & 69.2 & 56.5 & 36.2 & 36.5 \\
\hline \multicolumn{7}{|l|}{ Availability of a } \\
\hline \multicolumn{7}{|l|}{$\begin{array}{l}\text { Health Worker in } \\
\text { Community }\end{array}$} \\
\hline Not readily available & 22.8 & 21.2 & 79.8 & 50.2 & 28.8 & 29.2 \\
\hline Readily available & 30.4 & 28.5 & 80.4 & 68.5 & 42.4 & 39.4 \\
\hline \multicolumn{7}{|l|}{ Exposure to Media } \\
\hline Not exposed to media & 21.7 & 21.2 & 77.7 & 56.9 & 30.5 & 30.0 \\
\hline Exposed to media & 27.9 & 25.6 & 79.3 & 58.0 & 42.6 & 35.2 \\
\hline
\end{tabular}




\begin{tabular}{|c|c|c|c|c|c|c|}
\hline \multirow[t]{2}{*}{ Characteristics } & \multicolumn{2}{|c|}{ Early ANC } & \multicolumn{2}{|c|}{ Health Facility delivery } & \multirow{2}{*}{$\begin{array}{l}\text { EPNC } \\
\text { Eastern }\end{array}$} & \multirow[b]{2}{*}{ Western } \\
\hline & Eastern & Western & Eastern & Western & & \\
\hline \multicolumn{7}{|l|}{ Pregnancy Wanted } \\
\hline No & 17.4 & 18.5 & 77.8 & 57.3 & 40.3 & 35.3 \\
\hline Yes & 22.0 & 21.1 & 78.2 & 58.5 & 43.7 & 39.0 \\
\hline \multicolumn{7}{|l|}{ Complications } \\
\hline No & 23.5 & 22.9 & 77.1 & 57.2 & 20.2 & 19.5 \\
\hline Yes & 29.3 & 27.9 & 82.4 & 68.5 & 45.4 & 40.2 \\
\hline TOTAL & 28.1 & 25.1 & 77 & 57 & 43.3 & 38.9 \\
\hline
\end{tabular}

Note: level of significance ${ }^{*} \mathrm{p}<0.05$,

Results in Figure 1 reveal that disparities exist in the utilization of early ANC, HFD and EPNC between Eastern and Western women. The results show the biggest difference to be in health facility delivery $(20 \%)$. Western sub-region has a low utilization factor in all maternal health care services as compared to Eastern.

Decomposition of Differences in EANC, HFD and EPNC Services: A multivariate decomposition logistic regression model was used to decompose differences in EANC, HFD and EPNC between women in Eastern and Western sub-regions. The differentials are attributed to variation in their characteristics/ endowments (E) and variation in the effects of the predictors/coefficients (C) as indicated in Tables 3, 4, 5 and 6. Results in Table 3 reveal that differences in early ANC, health facility delivery and EPNC between the selected sub regions were significantly attributed to both variations in the characteristics and variations in effects of predictors $(\mathrm{p}<0.05)$. Overall, about $57.39 \%, 63.88 \%$ and $59.06 \%$ of the gap in EANC, HFD and EPNC respectively, is attributed to differences in characteristics of women. In contrast, $42.61 \%, 36.12 \%$ and $40.94 \%$ of the gap are attributed to differences in the effects of coefficients.

Figure 1: Multiple Bar Chart Showing Percentage Distribution of Women by EANC, HFD and EPNC

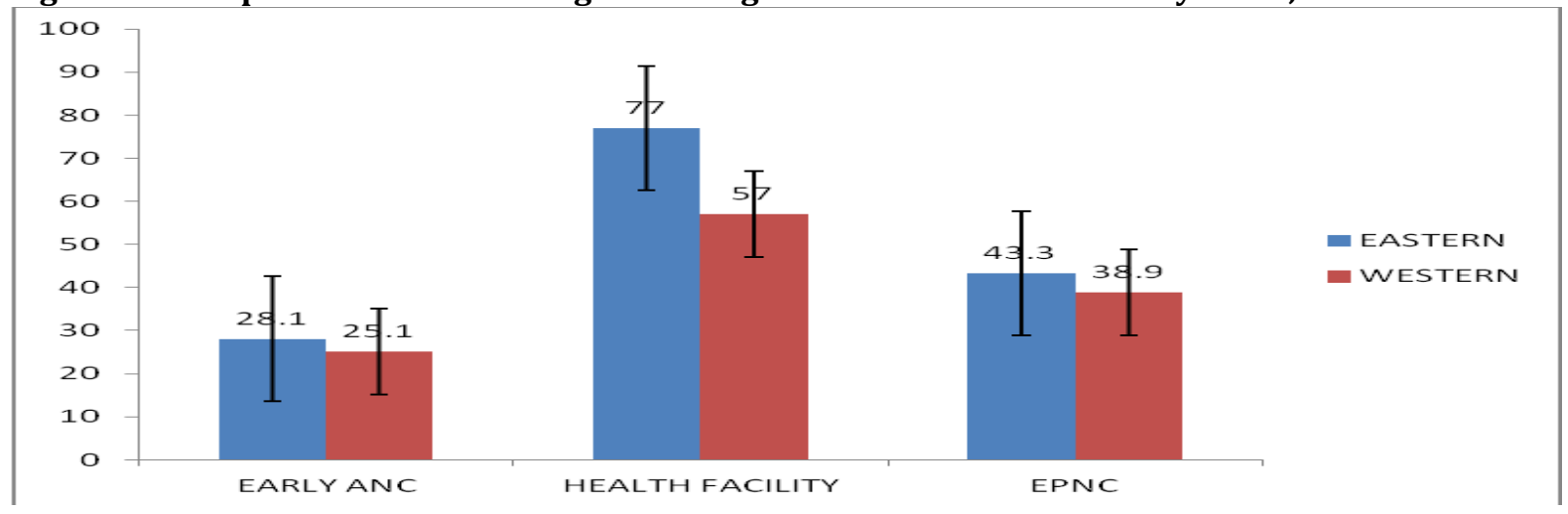

Table 3: Summary of Decomposition of Early ANC, Health Facility Delivery and EPNC Services

\begin{tabular}{lllllllllll}
\hline & \multicolumn{7}{l}{ Early ANC } & \multicolumn{7}{l}{ Health Facility Delivery } & \multicolumn{2}{c}{ EPNC } \\
\hline Components & Coef & p-value & $\mathbf{\%}$ & Coef & p-value & $\mathbf{\%}$ & Coef. & p-value & $\%$ \\
E & & & & & & & & & \\
C & 0.194 & 0.000 & 57.39 & 0.260 & 0.001 & 63.88 & 0.225 & 0.000 & 59.06 \\
& 0.145 & 0.000 & 42.61 & 0.147 & 0.000 & 36.12 & 0.156 & 0.003 & 40.94 \\
R & & & & & & & & & \\
& 0.339 & 0.000 & 100 & 0.407 & 0.001 & 100 & 0.381 & 0.003 & 100
\end{tabular}

Note: Overall decomposition results of early ANC, health facility delivery and EPNC; $n=1521$ : variations to differences in endowments (E) and effects of coefficients(C); $R$ is the total variation. 


\section{Decomposition of Early ANC Due to Differences in Characteristics and Effects of Coefficients}

Variations Due to Differences in Characteristics of Women: Overall, variation in the characteristics of women contributed about $57.39 \%$ to the overall gap in early ANC between the two sub regions. Specifically, at $5 \%$ level of significance, the differences were significantly attributed to maternal education (-6.5\%), marital status $(0.2 \%)$, availability of a health worker in the community $(34.72 \%)$, media exposure $(31.6 \%)$ and desire for pregnancy $(0.75 \%)$. In Turkey, strong demographic differentials existed between different nationals regardless of their socio-economic statuses (Koc, Hancioglu, \& Cavlin, 2008). The positive percentages indicate the proportion in which the total gap would decrease if the disparities in women's characteristics in the different sub regions were to disappear. In contrast, the negative percentage reveals the proportion to which the gap in early ANC would increase if the differences in the characteristics of women were to disappear. The overall gap in early ANC between Eastern and Western sub regions would reduce mainly if differences in availability of community health workers and media exposure were to disappear and increase without differences in maternal education.

Variations Due to Differences in Effects of Coefficients: Variations in the effects of coefficients on early ANC between Eastern and Western subregions contribute about $42.61 \%$ to the overall change, with the difference in intercepts accounting for this most. Specifically, the differences were significantly attributed to variation in the effects of maternal education (-68.8\%), wealth $(12.6 \%)$ and availability of health workers in the community $(2.4 \%)$ ( $\mathrm{p}<0.05$. Especially, the overall gap would increase on average by $68.8 \%, 12.6 \%$ and $2.4 \%$ in the absence of the variation in the effects of maternal education, wealth, and community health worker respectively.

Table 4: Decomposition of Early ANC Due to Differences in Characteristics and Effects of Coefficients

\begin{tabular}{|c|c|c|c|c|c|c|}
\hline \multirow[t]{2}{*}{ Variables } & \multicolumn{3}{|c|}{ Differences in Characteristics(E) } & \multicolumn{2}{|c|}{$\begin{array}{l}\text { Differences in } \\
\text { Coefficients(C) }\end{array}$} & \multirow{2}{*}{$\begin{array}{l}\text { Effects } \\
\text { Percent }\end{array}$} \\
\hline & Coefficient & p-value & Percent & Coefficient & p-value & \\
\hline \multicolumn{7}{|l|}{ Age } \\
\hline $15-19$ & 1.000 & & & 1.000 & & \\
\hline $20-34$ & -0.182 & 0.104 & -0.26 & -0.759 & 0.939 & -0.22 \\
\hline $35-49$ & 1.335 & 0.614 & -0.29 & -3.096 & 0.700 & -0.91 \\
\hline \multicolumn{7}{|l|}{ Highest Maternal } \\
\hline $\begin{array}{l}\text { Eaucation } \\
\text { Below primary }\end{array}$ & 1.000 & & & 1.000 & & \\
\hline Completed primary 7 & -8.394 & 0.002 & -2.48 & -120.341 & 0.014 & -23.40 \\
\hline Some secondary & -6.323 & 0.000 & -2.29 & -23.781 & 0.005 & -26.70 \\
\hline Completed secondary 6 & 0.089 & 0.017 & -1.73 & -12.012 & 0.036 & -18.70 \\
\hline \multicolumn{7}{|l|}{ Marital Status } \\
\hline Unmarried & 1.000 & & & .000 & & \\
\hline Married & 1.568 & 0.000 & 0.2 & -49.461 & 0.302 & -14.6 \\
\hline \multicolumn{7}{|l|}{ Wealth } \\
\hline Poor & 1.000 & & & 1.000 & & \\
\hline Middle & -4.819 & 0.822 & -1.4 & -33.948 & 0.008 & -10.02 \\
\hline Rich & -5.886 & 0.821 & -1.33 & -7.017 & 0.017 & -2.58 \\
\hline Distance to Health & & & & & & \\
\hline \multicolumn{6}{|l|}{ Facility } & \\
\hline $\begin{array}{l}\text { Not big problem } \\
\text { Big problem }\end{array}$ & -0.552 & 0.166 & -0.16 & 0.365 & 0.689 & 0.077 \\
\hline \multicolumn{7}{|l|}{ Cost of Service } \\
\hline Not big problem & 1.000 & & & 1.000 & & \\
\hline Big problem & -2.098 & 0.232 & -0.07 & -0.041 & 0.527 & -1.92 \\
\hline
\end{tabular}




\begin{tabular}{|c|c|c|c|c|c|c|c|}
\hline \multicolumn{8}{|c|}{$\begin{array}{l}\text { Journal of Economics and Behavioral Studies (ISSN: 2220-6140) } \\
\text { Vol. 13, No. 4, pp. 17-29, August } 2021\end{array}$} \\
\hline \multirow[t]{2}{*}{ Variables } & \multicolumn{3}{|c|}{ Differences in Characteristics(E) } & \multicolumn{2}{|c|}{$\begin{array}{l}\text { Differences in } \\
\text { Coefficients(C) }\end{array}$} & \multirow{2}{*}{$\begin{array}{l}\text { Effects } \\
\text { Percent }\end{array}$} & \\
\hline & Coefficient & p-value & Percent & Coefficient & p-value & & \\
\hline \multicolumn{8}{|l|}{ Worker in Community } \\
\hline \multicolumn{8}{|l|}{ Not readily available } \\
\hline Readily available & 1.000 & & & 1.000 & & & \\
\hline & 116.50 & 0.000 & 34.72 & -8.119 & 0.009 & -2.40 & \\
\hline \multicolumn{8}{|l|}{ Exposure to media } \\
\hline Not exposed media & 1.000 & & & 1.000 & & & \\
\hline Exposed to media & 1.369 & 0.002 & 31.6 & 12.439 & 0.319 & 3.67 & \\
\hline Pregnancy Wanted & & & & & & & \\
\hline No & 1.000 & & & 1.000 & & & \\
\hline Yes & 2.529 & 0.001 & 0.75 & 8.153 & 0.328 & -2.41 & \\
\hline \multicolumn{8}{|l|}{ Complications } \\
\hline No & 1.000 & & & 1.000 & & & \\
\hline Yes & -0.184 & 0.335 & -0.05 & 9.818 & 0.401 & 1.91 & \\
\hline Constant & & & & 494.080 & 0.053 & 145.223 & \\
\hline Total & 0.194 & 0.000 & 57.39 & 0.145 & 0.000 & 42.61 & \\
\hline
\end{tabular}

Decomposition of Health Facility Delivery Due to Differences in Characteristics and Effects of Coefficients

Variations Due to Differences in Characteristics of Women: Generally, variation in the characteristics of women contributed about $63.88 \%$ to the total gap in health facility delivery between Eastern and Western sub regions. Specifically, the differences were significantly attributed to the highest maternal education ($8.89 \%)$, community health worker availability (24.62\%), media exposure (34.7\%), and complicated pregnancy $(-0.01 \%)(\mathrm{p}<0.05)$. The overall gap in health facility delivery between women in Eastern and Western regions would reduce on average by $24.62 \%$ and $37.2 \%$ of differences in availability of a health worker in the community and media exposure were to disappear respectively and would increase mainly on average by $8.89 \%$ at the disappearance of the differences in highest maternal education.

Variations Due to Differences in Effects of Predictors: Variations in the effects of predictors on HFD among women in Eastern and Western subregions contribute about $36.12 \%$ to the overall change. The difference in intercepts accounted for most of the changes. Specifically, the differences were significantly attributed to variation in the effects of maternal education $(-54.9 \%)$ and wealth $(8.69 \%)(p<0.05)$. In particular, the overall gap in health facility delivery would increase on average by $54.9 \%$ in the absence of the variation in the effects of maternal education and reduce on average by $8.69 \%$ in the absence of the variation in the effects of wealth.

Table 5: Decomposition of Health Facility Delivery Due to Differences in Characteristics and Effects of Predictors

\begin{tabular}{|c|c|c|c|c|c|c|}
\hline \multirow[t]{2}{*}{ Variables } & \multicolumn{3}{|c|}{ Differences in Characteristics (E) } & \multicolumn{2}{|c|}{$\begin{array}{l}\text { Differences in } \\
\text { Coefficients(C) }\end{array}$} & \multirow{2}{*}{$\begin{array}{c}\text { Effects } \\
\text { Percent }\end{array}$} \\
\hline & Coefficient & p-value & Percent & Coefficient & p-value & \\
\hline \multicolumn{7}{|l|}{ Age } \\
\hline $15-19$ & 1.000 & & & 1.000 & & \\
\hline $20-34$ & -0.452 & 0.35 & 0.00 & 0.370 & 0.067 & -0.78 \\
\hline $35-49$ & 0.631 & 0.091 & 2.00 & 0.096 & 0.730 & -1.3 \\
\hline Education & & & & & & \\
\hline Below primary & 1.000 & & & 1.000 & & \\
\hline Completed primary 7 & 5.430 & 0.031 & -3.50 & -74.481 & 0.042 & -17.80 \\
\hline Some secondary & -1.327 & 0.001 & -0.50 & -24.532 & 0.000 & -22.40 \\
\hline
\end{tabular}




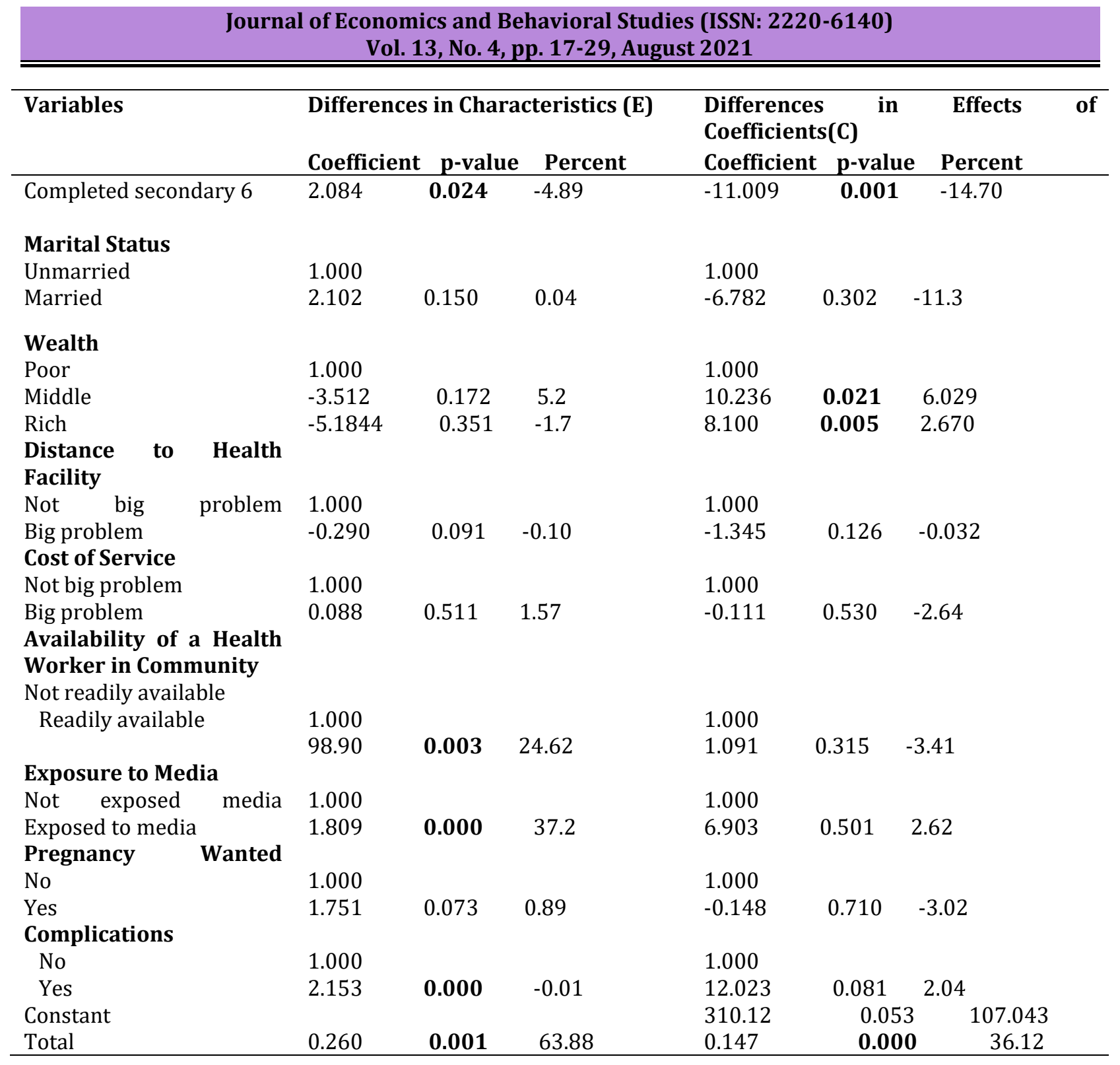

\section{Decomposition of EPNC Due to Differences in Characteristics and Effects of Coefficients}

Variations Due to Differences in Characteristics of Women: Variations in the women's characteristics contributed about $59.06 \%$ to the overall gap in EPNC between Eastern and Western sub regions. Specifically, the differences were significantly attributed to maternal education (18.52\%), marital status $(0.34 \%)$ and availability of a health worker in the community $(17.17 \%)(\mathrm{p}<0.05)$. The overall gap in EPNC between the two sub regions would reduce mainly on average by $18.52 \%$ and $17.17 \%$ of differences in maternal education and availability of community health workers were to disappear.

Variations Due to Differences in Effects of Predictors: Variations in the coefficients or effects of predictors on EPNC between women in Eastern and Western subregions contribute about $40.94 \%$ to the total change, mostly with the difference in the intercepts. Precisely, the differences were significantly attributed to variation in the effects of maternal education $(-52.8 \%)$, wealth $(-8.4 \%)$ and availability of health workers in the community $(-4.7 \%)(\mathrm{p}<0.05)$. In particular, the overall gap in EPNC would increase on average by $52.8 \%$, $8.4 \%$ and $4.7 \%$ in the absence of the variation in the effects of maternal education, wealth, and health worker availability in the community respectively. 


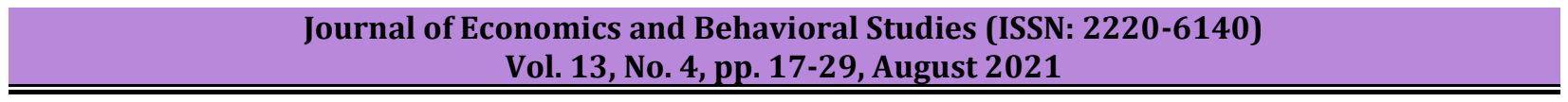

Table 6: Decomposition of EPNC Due to Differences in Characteristics and Effects of Coefficients

\begin{tabular}{|c|c|c|c|c|c|c|}
\hline \multirow[t]{2}{*}{ Variables } & \multicolumn{3}{|c|}{ Differences in Characteristics (E) } & \multicolumn{3}{|c|}{$\begin{array}{l}\text { Differences in Effects of Coefficients } \\
\text { (C) }\end{array}$} \\
\hline & Coefficient & p-value & Percent & Coefficient & p-value & e Percent \\
\hline \multicolumn{7}{|l|}{ Age } \\
\hline $15-19$ & 1.000 & & & 1.000 & & \\
\hline $20-34$ & -0.440 & 0.231 & 1.60 & -0.191 & 0.149 & -0.62 \\
\hline $35-49$ & -1.323 & 0.181 & -2.04 & -1.62 & 0.07 & -1.11 \\
\hline Highest Maternal & & & & & & \\
\hline \multicolumn{7}{|l|}{ Education } \\
\hline Below primary & 1.000 & & & 1.000 & & \\
\hline Completed primary 7 & 12.24 & 0.045 & 13.5 & -34.23 & 0.004 & -20.10 \\
\hline Some secondary & 10.32 & 0.010 & 3.00 & -2.791 & 0.025 & -23.00 \\
\hline Completed secondary 6 & 1.089 & 0.007 & 2.02 & 0.012 & 0.011 & -9.70 \\
\hline \multicolumn{7}{|l|}{ Marital Status } \\
\hline Unmarried & 1.000 & & & .000 & & \\
\hline Married & 1.568 & 0.006 & 0.34 & -32.404 & 0.140 & -2.43 \\
\hline \multicolumn{7}{|l|}{ Wealth } \\
\hline Poor & 1.000 & & & 1.000 & & \\
\hline Middle & -3.839 & 0.236 & -3.03 & -10.921 & 0.019 & -6.43 \\
\hline Rich & -2.832 & 0.070 & -2.79 & -3.324 & 0.007 & -1.97 \\
\hline Distance to Health & & & & & & \\
\hline \multicolumn{7}{|l|}{ Facility } \\
\hline Not big problem & 1.000 & & & 1.000 & & \\
\hline Big problem & 0.342 & 0.136 & -0.15 & -0.315 & 0.919 & 0.47 \\
\hline \multicolumn{7}{|l|}{ Cost of Service } \\
\hline Not big problem & 1.000 & & & 1.000 & & \\
\hline Big problem & 1.018 & 0.114 & -0.37 & -0.249 & 0.316 & -1.39 \\
\hline \multicolumn{7}{|l|}{$\begin{array}{l}\text { Availability of a Health } \\
\text { Worker in Community }\end{array}$} \\
\hline \multicolumn{7}{|l|}{ Not readily Available } \\
\hline \multirow[t]{2}{*}{ Readily available } & 1.000 & & & 1.000 & & \\
\hline & 98.20 & 0.03 & 17.17 & -2.321 & 0.025 & -4.70 \\
\hline \multicolumn{7}{|l|}{ Exposure to Media } \\
\hline Not exposed media & 1.000 & & & 1.000 & & \\
\hline Exposed to media & 2.219 & 0.283 & 31.68 & 8.210 & 0.523 & 4.07 \\
\hline Pregnancy Wanted & & & & & & \\
\hline No & 1.000 & & & 1.000 & & \\
\hline Yes & -0.029 & 0.120 & -3.56 & 3.230 & 0.068 & -5.01 \\
\hline \multicolumn{5}{|l|}{ Complicated Pregnancy } & \multicolumn{2}{|c|}{ No } \\
\hline \multirow[t]{2}{*}{ Yes } & 1.000 & & & 1.000 & & \\
\hline & -0.097 & 0.92 & -1.13 & 7.085 & 0.330 & -2.02 \\
\hline \multicolumn{7}{|l|}{ Constant } \\
\hline Total & 0.225 & 0.000 & 59.06 & $\begin{array}{l}345.01 \\
0.156\end{array}$ & $\begin{array}{l}0.621 \\
\mathbf{0 . 0 0 3}\end{array}$ & $\begin{array}{c}17.91 \\
40.94\end{array}$ \\
\hline
\end{tabular}

\section{Discussion of Results}

Our findings show a relatively large regional gap in the use of maternal healthcare services (MHCS) between Eastern and Western sub-regions in Uganda. The main factors that contributed to the gap were the highest maternal education and community health worker availability followed by media exposure and wealth. A 
similar study found significant inequalities in the early use of maternal health services in Malawi due to different geographical locations, education and wealth (Yaya et al., 2016). In Nigeria, pregnant women from impoverished backgrounds with a low level of education were less likely to receive early maternal services (Adeyanju et al., 2017), confirmed in China (Liu et al., 2014), Bangladesh, (Khan et al., 2018) and India (Pallikadavath et al., 2004a). The higher contribution of maternal education in the overall regional gap in all indicators could be understood through the association of education with increasing migrations. Due to the fact that many people move from different regions to the Western sub-region looking for work evidenced by the highest percentage of recent female internal migrants (UBOS, 2017) and high annual regional population growth. Among this population of women, this results in less awareness and underuse of services. The significant contribution of community health worker availability may be attributed to a higher concentration of health workers leading to ease of use (Malarcher et al., 2011).

As well as more support organizations in the Eastern than Western sub-region. Western sub-region is considered a geographically disadvantaged sub-region in Uganda because of acculturation of mixed tribes (the Bafuliki Bakiga, Banyankole) and constant migrations from Congo, which limits women's awareness of health services (Isarabhakdi, 2004; Shaokang, Zhenwei, \& Blas, 2002; Van der Stuyft, De Muynck, Schillemans, \& Timmerman, 1989). Notably, findings indicate that wealth lowers the average gap in utilization of early antenatal care, health facility delivery and EPNC between the two sub regions. This may be explained by the fact that better economic stand is associated with relatively better education status and affordable cost of service, both of which are favorable for better use of healthcare services (Kiwanuka et al., 2008; Ssewanyana \& Kasirye, 2012; Zere et al., 2010). In sum, there exists delayed use of maternal health services with enormous regional disparities due to socioeconomic differences in Uganda. Hence, there is a need for fairness and equity in education, wealth, increasing information service coverage, and even distribution of essential maternal health community services across the country.

Limitation of the Study: This study used secondary data which was collected through a retrospective investigation that is often susceptible to memory lapse and recall biases. For example, information obtained concerning wealth and distance to a health facility reflected the situation at the time of the inquiry and not the time the mother delivered, and hence they may have shifted from one group of classification into another which might have affected the results. Furthermore, the time for first antenatal care attainment might not be recalled exactly, which may impact the precision of the findings. Reports of only alive women at the time of the survey were obtained, moreover, in Uganda where the maternal mortality ratio is very high, essential information on mothers who succumbed during childbirth could have contributed to the study.

\section{Conclusion and Recommendations}

There exist regional inequalities in the utilization of early antenatal care, health facility delivery and EPNC among women in Uganda. The critical variations are mainly due to differences in maternal education level, availability of health workers in the community, exposure to media and wealth. To address the significant disparities, this study proposes two main strategies: Ensuring strong and even allocation of community health workers without distinction of demographic, social and economic conditions across all regions, and Government of Uganda and other stakeholders emphasizing girl child education completion, equal broad dissemination of maternal health and continuum of care information across the country and passing the pending bill on insurance to reduce costs of accessing maternal health services.

In Essence: Equity is paramount in improving early maternal health care utilization in Uganda.

Declarations: Ethics Approval and Consent to Participate. The Uganda Demographic and Health Survey (UDHS) conducted during the period 2015/16 were used in this study. This UDHS series is a nationally crosssectional survey implemented by the Uganda Bureau of Statistics (UBOS) that provides information on key demographic and population characteristics for giving up-to-date maternal health indicators. Consent and authorization to make use of the data were acquired from ICF Macro International U.S.A, DHS Program based on our previous study (Atuhaire, Atuhaire, Wamala, \& Nansubuga, 2020). Participants expressed their consent before the start of the interview as stated by the data originator. 
Availability of Data and Materials: The datasets retrieved and used during this study are not publicly available due to a requirement of approval from ICF Macro International U.S.A. The authors obtained authorization to use "Survey" data from the Demographic and Health Surveys (DHS) Program accessed on: http://www.dhsprogram.com/data/dataset_admin/login_main.cfm. The approval letter is, therefore, attached for confirmation.

Competing Interests: The authors declare that they have no competing interests.

Author's Contributions: RA conceived the study, retrieved data, analyzed the data, prepared this Manuscript, reviewed literature, and interpreted the findings. RW conceptualized the study, developed the Methodology, and substantively reviewed the Manuscript. LKA and EN contributed to identifying and classification of variables, preparing the manuscript, and improving the scientific content of the study. The authors read, reviewed, edited, and authorized the final manuscript.

Acknowledgments: The authors are most grateful to the Uganda Bureau of Statistics (UBOS) and ICF Macro International Inc. for providing the dataset. Our gratitude goes to esteemed Scholars JohnBosco Asiimwe, Betty Kwagala, Cyprian Misinde, and Stephen Ojiambo Wandera for their invaluable guidance and advice in this research, and McConnell Abby from the Naval Postgraduate School, Monterey who edited this work. We would like to thank the management of Makerere University Business School (MUBS) under the ADB-HEST project for facilitating the Ph.D. study undertaken by Ruth Atuhaire from which this manuscript has been developed. The contents of this manuscript are solely the responsibility of the authors and do not necessarily represent the official views of the supporting offices.

\section{References}

Adeyanju, O., Tubeuf, S. \& Ensor, T. (2017). Socio-economic inequalities in access to maternal and child healthcare in Nigeria: changes over time and decomposition analysis. Health policy and planning, 32(8), 1111-1118.

Alexander, G. R., Kogan, M. D. \& Nabukera, S. (2002). Racial differences in prenatal care use in the United States: Are disparities decreasing? American Journal of Public Health, 92(12), 1970-1975.

Arthur, E. (2012). Wealth and antenatal care use: implications for maternal health care utilization in Ghana. Health economics review, 2(1), 14.

Atuhaire, R., Atuhaire, L. K., Wamala, R. \& Nansubuga, E. (2020). Interrelationships between early antenatal care, health facility delivery and early postnatal care among women in Uganda: a structural equation analysis. Global health action, 13(1), 1830463.

Bbaale, E. \& Guloba, A. (2011). Maternal education and childbirth care in Uganda. The Australasian medical journal, 4(7), 389.

Boutayeb, A. \& Helmert, U. (2011). Social inequalities, regional disparities and health inequity in North African countries. International journal for equity in health, 10(1), 23.

de Graaf, J. P., Steegers, E. A. \& Bonsel, G. J. (2013). Inequalities in perinatal and maternal health. Current Opinion in Obstetrics and Gynecology, 25(2), 98-108.

Emelumadu, O., Ukegbu, A., Ezeama, N., Kanu, O., Ifeadike, C. \& Onyeonoro, U. (2014). Socio-demographic determinants of maternal health-care service utilization among rural women in Anambra State, southeast Nigeria. Ann Med Health Sci Res, 4. doi: 10.4103/2141-9248.133463

Fang, P., Dong, S., Xiao, J., Liu, C., Feng, X. \& Wang, Y. (2010). Regional inequality in health and its determinants: evidence from China. Health policy, 94(1), 14-25.

Golooba-Mutebi, F. (2011). Maternal health delivery in Rwanda and Uganda: exploring sources of success and failure. Paper presented at the Rethinking Development in an Age of Scarcity and Uncertainty conference, DSA/EADI, York.

Houweling, T. A., Ronsmans, C., Campbell, O. M. \& Kunst, A. E. (2007). Huge poor-rich inequalities in maternity care: an international comparative study of maternity and child care in developing countries. Bulletin of the World Health Organization, 85, 745-754.

Isarabhakdi, P. (2004). Meeting at the Crossroads: Myanmar Migrants and Their Use of Thai Health Care Services. Asian and Pacific Migration Journal, 13(1), 107-126. DOI: 10.1177/011719680401300106 
Kerber, K. J., de Graft-Johnson, J. E., Bhutta, Z. A., Okong, P., Starrs, A. \& Lawn, J. E. (2007). Continuum of care for maternal, newborn, and child health: from slogan to service delivery. The Lancet, 370(9595), 1358-1369.

Khan, Islam, M. \& Rahman, M. (2018). Inequality in utilization of cesarean delivery in Bangladesh: a decomposition analysis using nationally representative data. Public health, 157, 111-120.

Kiwanuka, S., Ekirapa, E., Peterson, S., Okui, O., Rahman, M. H., Peters, D. \& Pariyo, G. (2008). Access to and utilization of health services for the poor in Uganda: a systematic review of available evidence. Transactions of the Royal Society of Tropical Medicine and Hygiene, 102(11), 1067-1074.

Koc, I., Hancioglu, A. \& Cavlin, A. (2008). Demographic differentials and demographic integration of Turkish and Kurdish populations in Turkey. Population Research and Policy Review, 27(4), 447-457.

Lavado, R. F. \& Lagrada, L. P. (2008). Are there Regional Variations in the Utilization of Maternal and Child Care Services across Income Groups? Philippine Journal of Development, 35(2), 53-75.

Liu, X., Gao, W. \& Yan, H. (2014). Measuring and decomposing the inequality of maternal health services utilization in western rural China. BMC health services research, 14(1), 102.

Magadi, M. A., Zulu, E. M. \& Brockerhoff, M. (2003). The inequality of maternal health care in urban sub-Saharan Africa in the 1990s. Population Studies, 57(3), 347-366.

Malarcher, S., Meirik, O., Lebetkin, E., Shah, I., Spieler, J. \& Stanback, J. (2011). Provision of DMPA by community health workers: what the evidence shows. Contraception, 83(6), 495-503.

Navaneetham, K. \& Dharmalingam, A. (2002). Utilization of maternal health care services in Southern India. Social science \& medicine, 55(10), 1849-1869.

Norton, R. (2016). Women's health: a new global agenda. Women's Health, 12(3), 271-273.

Ononokpono, D. N. \& Odimegwu, C. O. (2014). Determinants of maternal health care utilization in Nigeria: a multilevel approach. The Pan African Medical Journal, 17(Suppl 1).

Pal, R. (2015). Inequality in maternal health care utilization in India: a Shapley decomposition analysis. Journal of International Development, 27(7), 1141-1152.

Pallikadavath, S., Foss, M. \& Stones, R. W. (2004a). Antenatal care in rural Madhya Pradesh: provision and inequality. Obstetric Care in Central India, 111-128.

Pallikadavath, S., Foss, M. \& Stones, R. W. (2004b). Antenatal care: provision and inequality in rural north India. Social science \& medicine, 59(6), 1147-1158.

Rai, Singh, P. K. \& Singh, L. (2012). Utilization of maternal health care services among married adolescent women: insights from the Nigeria Demographic and Health Survey, 2008. Women's Health Issues, 22(4), e407-e414.

Rice, M. (2019). Maternal Health \& Rights In Uganda.

Ricketts, T. C. \& Goldsmith, L. J. (2005). Access in health services research: the battle of the frameworks. Nursing Outlook, 53(6), 274-280.

Rutaremwa, G., Wandera, S. O., Jhamba, T., Akiror, E. \& Kiconco, A. (2015). Determinants of maternal health services utilization in Uganda. BMC health services research, 15(1), 271.

Say, L. \& Raine, R. (2007). A systematic review of inequalities in the use of maternal health care in developing countries: examining the scale of the problem and the importance of context. Bulletin of the World Health Organization, 85, 812-819.

Shaokang, Z., Zhenwei, S. \& Blas, E. (2002). Economic transition and maternal health care for internal migrants in Shanghai, China. Health policy and planning, 17(suppl_1), 47-55.

Singh, P. K., Rai, R. K., Alagarajan, M. \& Singh, L. (2012). Determinants of maternity care services utilization among married adolescents in rural India. PLOS ONE, 7(2), e31666.

Ssewanyana, S. \& Kasirye, I. (2012). Causes of health inequalities in Uganda: evidence from the demographic and health surveys. African Development Review, 24(4), 327-341.

Stata, S. (2013). Release 13. statistical software. StataCorp LP, College Station, TX.

Tran, T. K., Nguyen, C. T., Nguyen, H. D., Eriksson, B., Bondjers, G., Gottvall, K. \& Petzold, M. (2011). Urbanrural disparities in antenatal care utilization: a study of two cohorts of pregnant women in Vietnam. $B M C$ health services research, 11(1), 120.

UBOS, I. (2017). Uganda demographic and health survey. Uganda Bureau of Statistics, Kampala Uganda.

UNICEF. (2019). Maternal, newborn, child and adolescent health. WHO. https://www.unicef.org/pressreleases/surviving-birth-every-11-seconds-pregnant-w.

Van der Stuyft, P., De Muynck, A., Schillemans, L. \& Timmerman, C. (1989). Migration, acculturation and utilization of primary health care. Social Science \& Medicine, 29(1), 53-60. 
Victora, C. G., Aquino, E. M., do Carmo Leal, M., Monteiro, C. A., Barros, F. C. \& Szwarcwald, C. L. (2011). Maternal and child health in Brazil: progress and challenges. The lancet, 377(9780), 1863-1876.

WHO. (2015a). WHO recommended interventions for improving maternal and newborn health: integrated management of pregnancy and childbirth: Geneva: World Health Organization.

WHO. (2015b). WHO, Health in 2015: from MDGs, Millennium Development Goals to SDGs, Sustainable Development Goals, Geneva, Switzerland, 2015. . SDGs), Transforming our world: the, 2030.

WHO. (2017). World health statistics 2017: monitoring health for the SDGs, Sustainable Development Goals. Geneva: World Health Organization; 2017. Licence: CC BY-NC-SA 3.0 IGO. (https://creativecommons.org/licenses/by-nc-sa/3.0/igo).).

WHO. (2019). Trends in maternal mortality: Key facts. developed by WHO, UNICEF, UNFPA and The World Bank, Available on https://www.who.int/news-room/fact-sheets/detail/maternal-mortality.

Wudineh, K. G., Nigusie, A. A., Gesese, S. S., Tesu, A. A. \& Beyene, F. Y. (2018). Postnatal care service utilization and associated factors among women who gave birth in Debretabour town, North West Ethiopia: a community-based cross-sectional study. BMC pregnancy and childbirth, 18(1), 508.

Yaya, S., Bishwajit, G. \& Shah, V. (2016). Wealth, education and urban-rural inequality and maternal healthcare service usage in Malawi. BMJ global health, 1(2), e000085.

Zere, E., Oluwole, D., Kirigia, J. M., Mwikisa, C. N. \& Mbeeli, T. (2011). Inequities in skilled attendance at birth in Namibia: a decomposition analysis. BMC pregnancy and childbirth, 11(1), 34.

Zere, E., Tumusiime, P., Walker, O., Kirigia, J., Mwikisa, C. \& Mbeeli, T. (2010). Inequities in utilization of maternal health interventions in Namibia: implications for progress towards MDG 5 targets. International journal for equity in health, 9(1), 16. 